ISSN electrónico: 1585-5210

DOI: https://doi.org/10.14201/rmc.27925

\title{
VIRUELA THE KILLER THAT STALKED NEW YORK
}

\author{
María GARCÍA MOROㄹ; Enrique GARCÍA MERINO²; Enrique GARCÍA SÁNCHEZ ${ }^{345}$ (D); Jose Elías GARCÍA \\ SÁNCHEZ ${ }^{6}$ \\ ${ }^{1}$ IQVIA. Madrid (España). ${ }^{2}$ Departamento de Sanidad, IES Martínez Uribarri, Salamanca (España). \\ ${ }^{3}$ Departamento de Ciencias Biomédicas y del Diagnóstico. Facultad de Medicina. Universidad de Salamanca \\ (España). ${ }^{4}$ IUCE (Instituto Universitario de Ciencias de la Educación). Universidad de Salamanca (España). \\ ${ }^{5}$ IBSAL (Instituto de Investigación Biomédica de Salamanca) (España). ${ }^{6}$ Universidad de Salamanca.
}

\section{Ficha técnica}

Título: The Killer That Stalked New York.

Título original: The Killer That Stalked New York. País: Estados Unidos.

Año: 1950.

Director: Earl McEvoy.

Música: Hans J. Salter.

Fotografía: Joseph Biroc.

Montaje: Jerome Thoms.

Guion: Harry Essex basado en el articulo Smallpox, the Killer That Stalks New York de Milton Lehman (Cosmopolitan Magazine).

Intérpretes: Evelyn Keyes, Charles Korvin, William Bishop, Dorothy Malone, Lola Albright, Barry Kelley, Carl Benton Reid, Ludwig Donath, Art Smith, Whit Bissell, Roy Roberts, Connie Gilchrist, Dan Riss. Harry Shannon, Jim Backus, Jay Barney, George Baxter, Eumenio Blanco.

Color: Blanco y negro.

Duración: 79 minutos.
Género: Drama, cine negro. Thriller, infección. viruela.

Idioma original: Inglés.

Productoras: Robert Cohn Productions.

Sinopsis: Una mujer llega Nueva York desde Cuba llevando sin saberlo la muerte encima, es portadora del virus de la viruela, cantante y contrabandista de diamantes. Por esta causa es seguida de cerca por un policía de aduanas. Nada más llegar empieza a sentirse mal y a contagiar a aquellos con los que tiene un contacto estrecho. La ciudad se enfrenta a un enemigo inusual, hay que localizarla para bloquearlo, en esta tarea acabaran trabajando codo con codo sanitarios, policía y políticos.

Disponibilidad: Dominio público.

Enlaces:

Imdb: https://www.imdb.com/title/tt0042643

Trailer:

https://www.youtube.com/watch?v=uw6F909FGco 


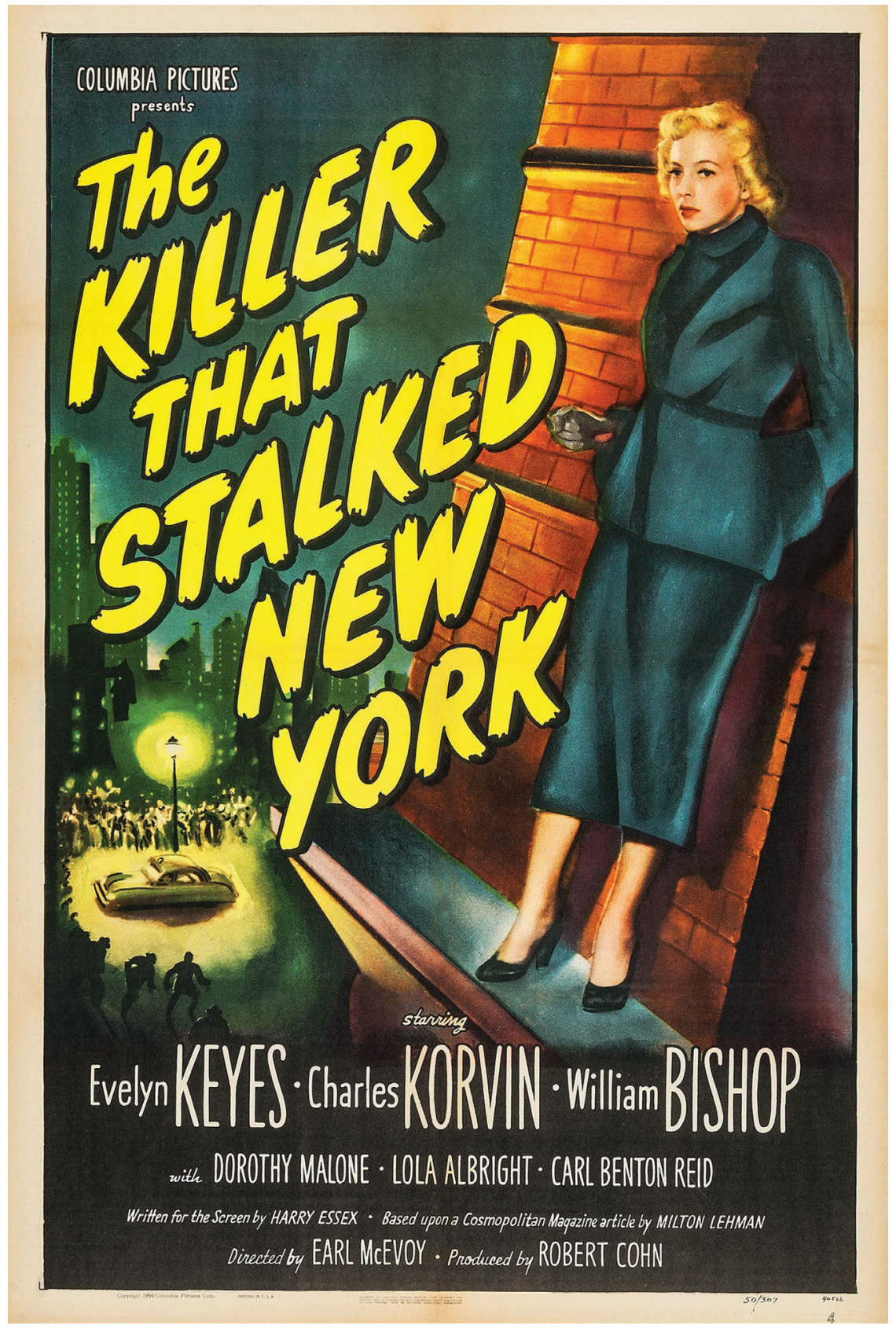

Cartel norteamericano

Acción: Nueva York (EEUU). Época 1947 


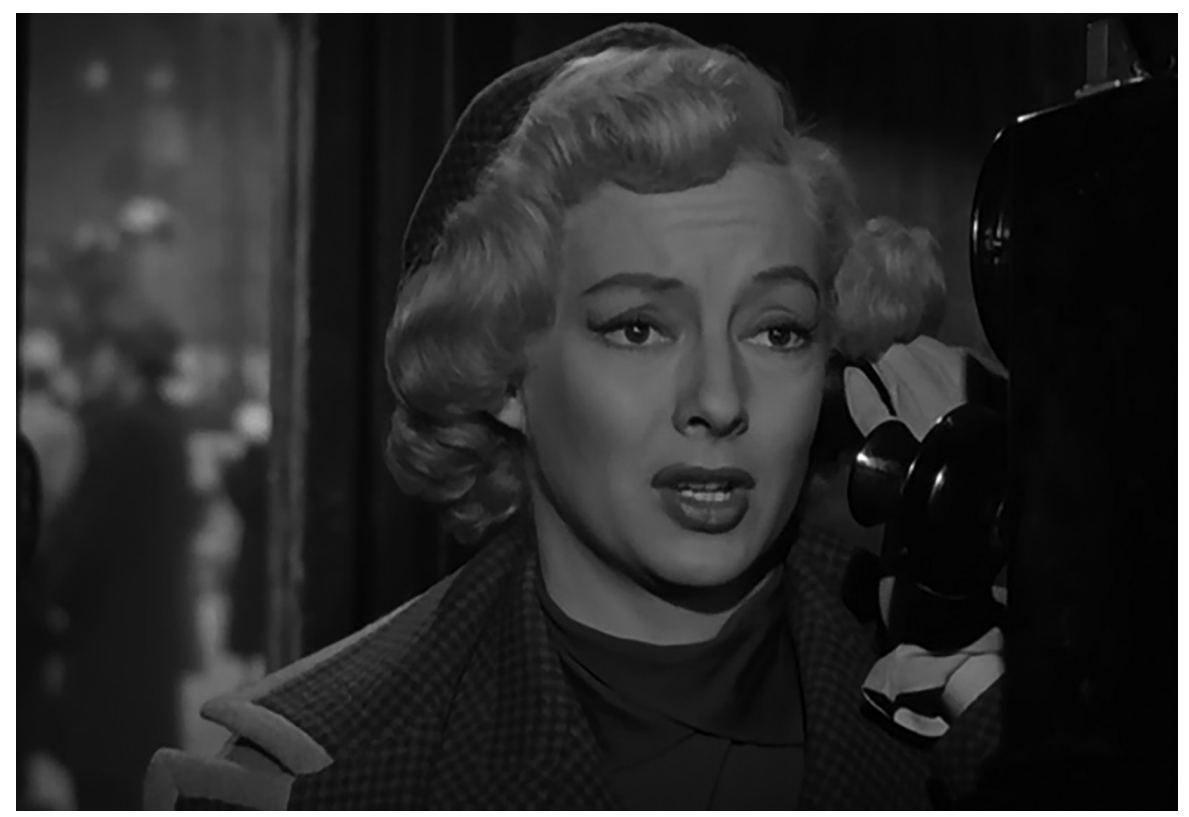

Fotograma 1. Portador asintomático (casi)

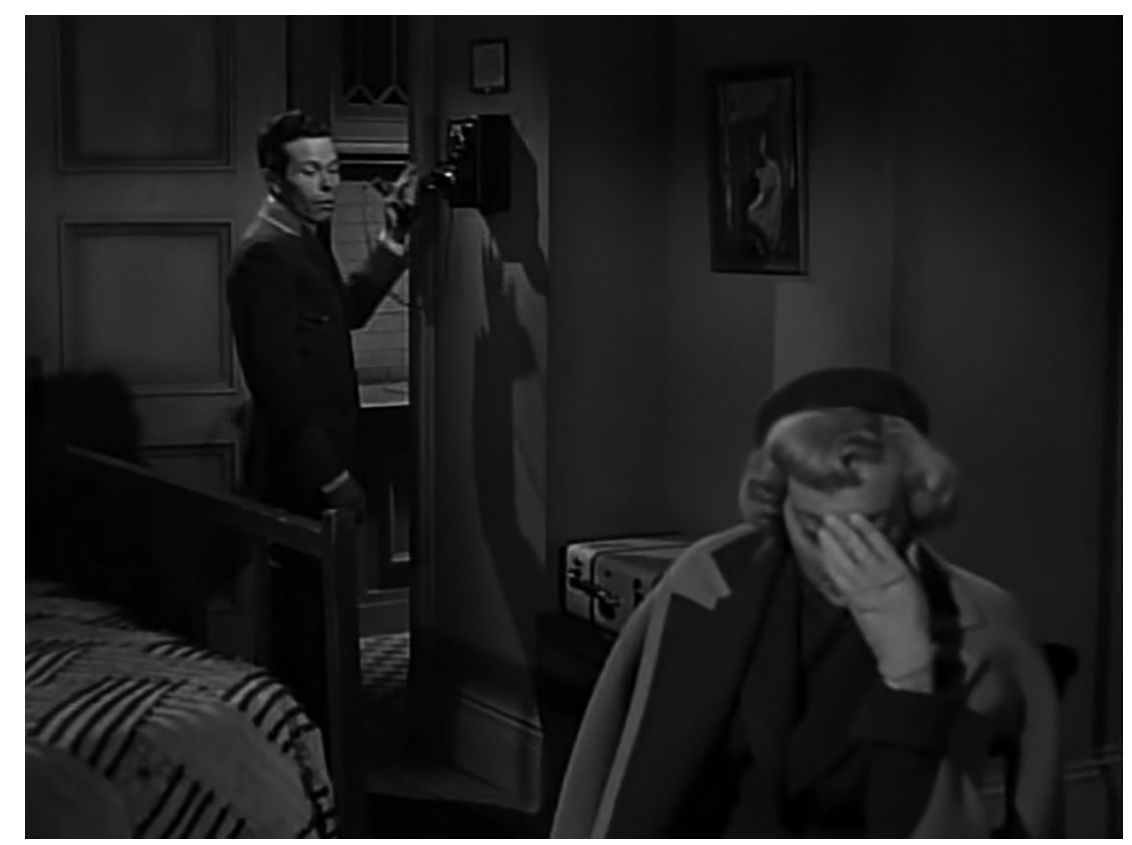

Fotograma 2. Dolor de cabeza 


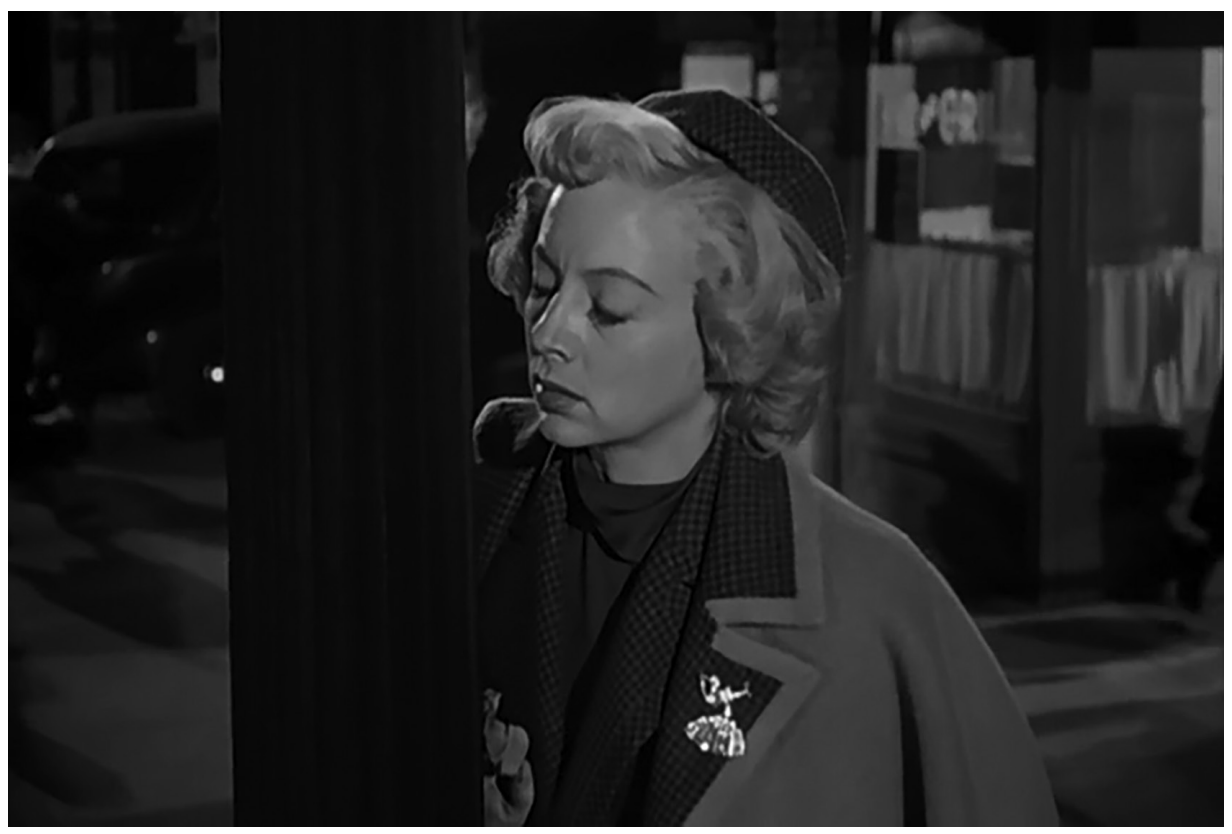

Fotograma 3. Malestar general y fatiga

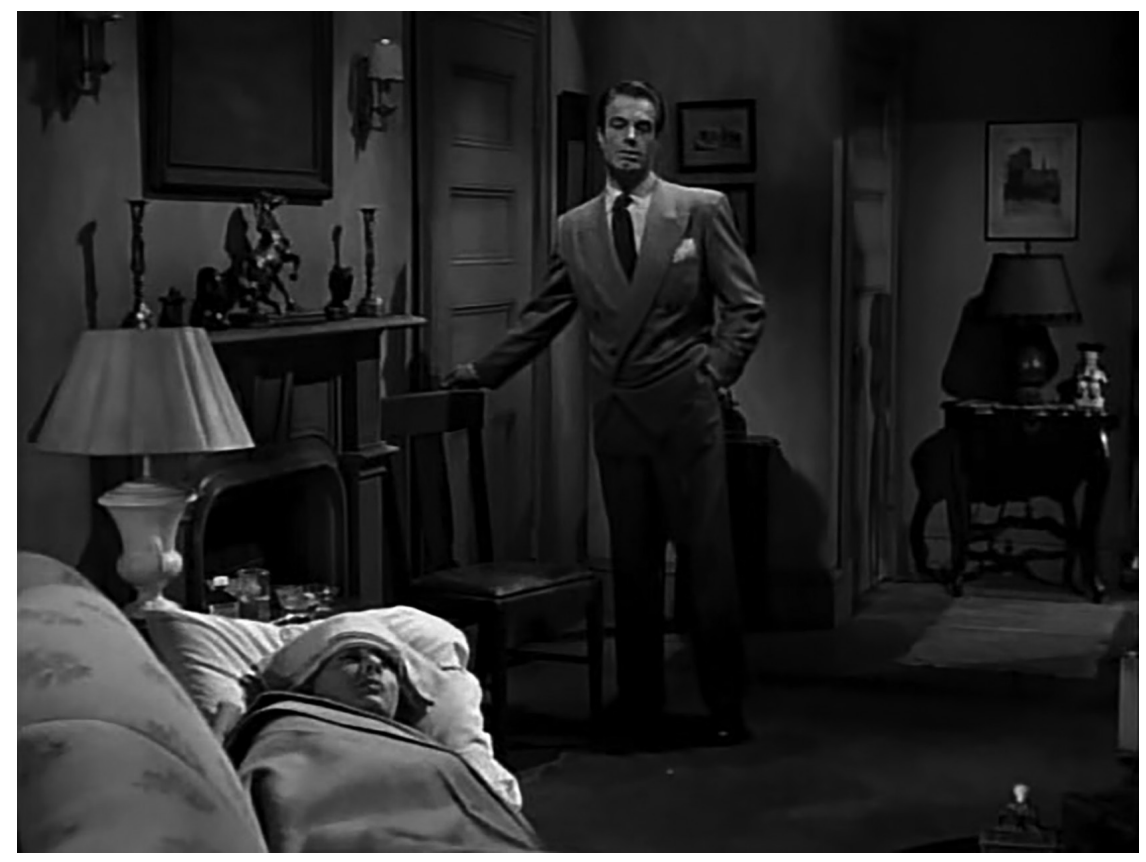

Fotograma 4. Fiebre y postración 


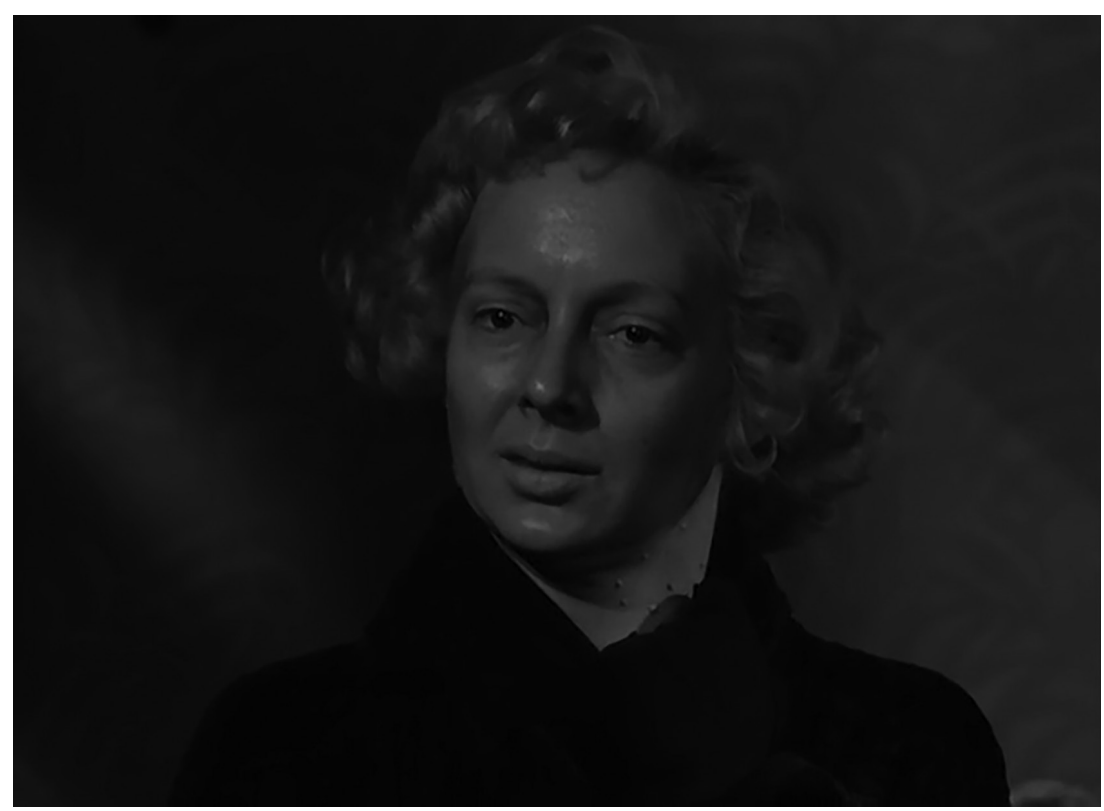

Fotograma 5. Exantema y muy mal estado general

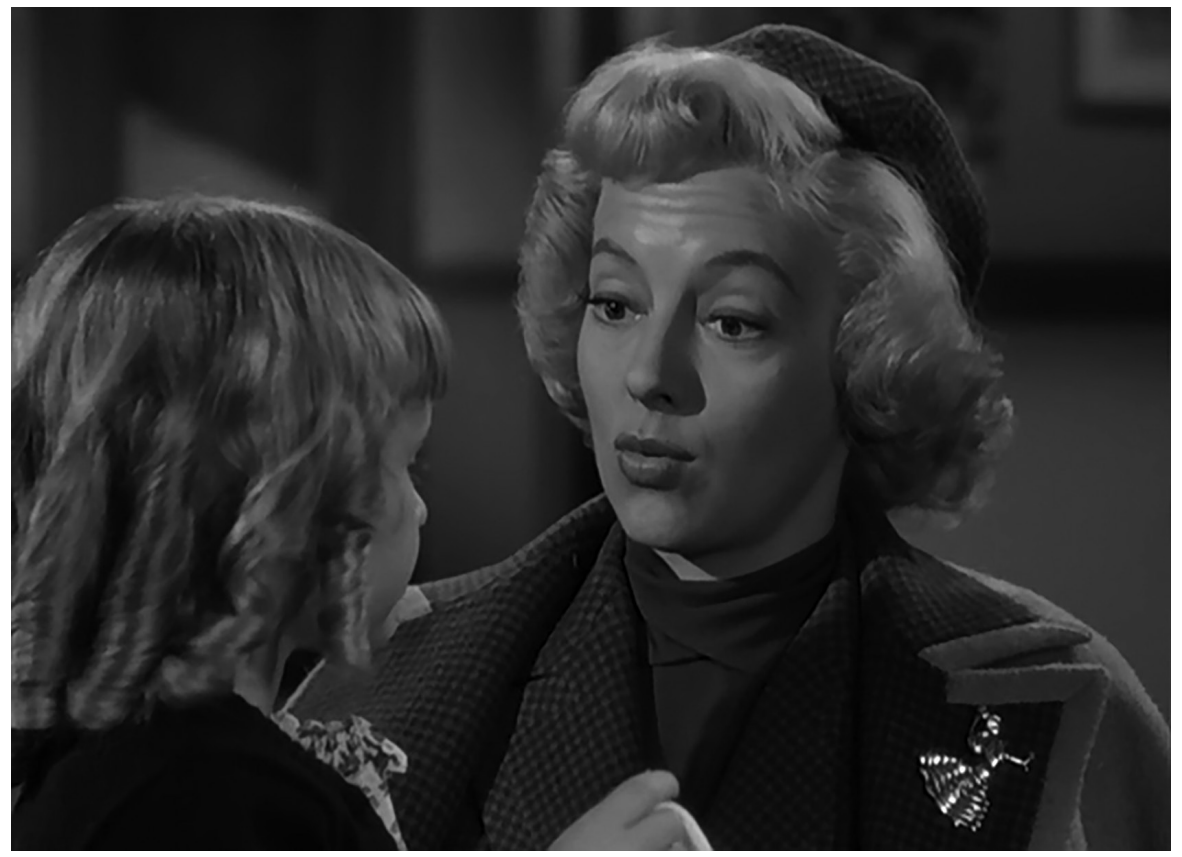

Fotograma 6. Trasmisión por contacto directo por vía aérea. Relación estrecha y prolongada entre la mujer y una niña 


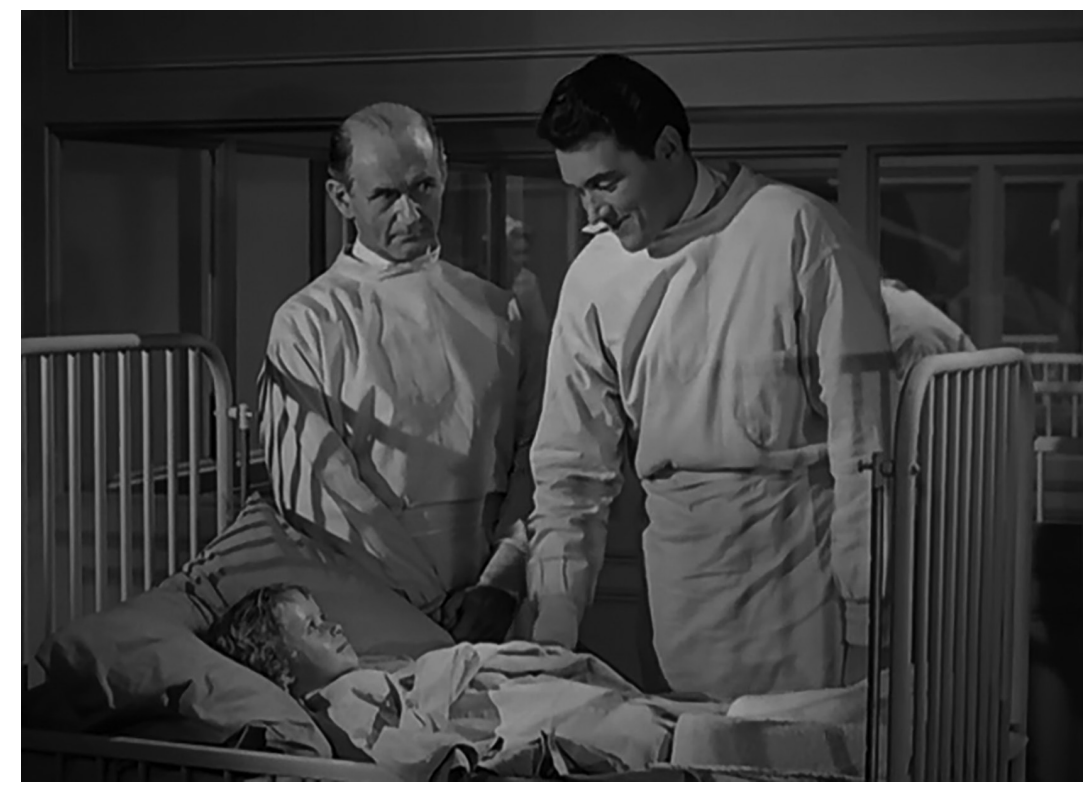

Fotograma 7. Tras el periodo de incubación la pequeña presenta cefalea, dolor de espalda, fiebre y exantema

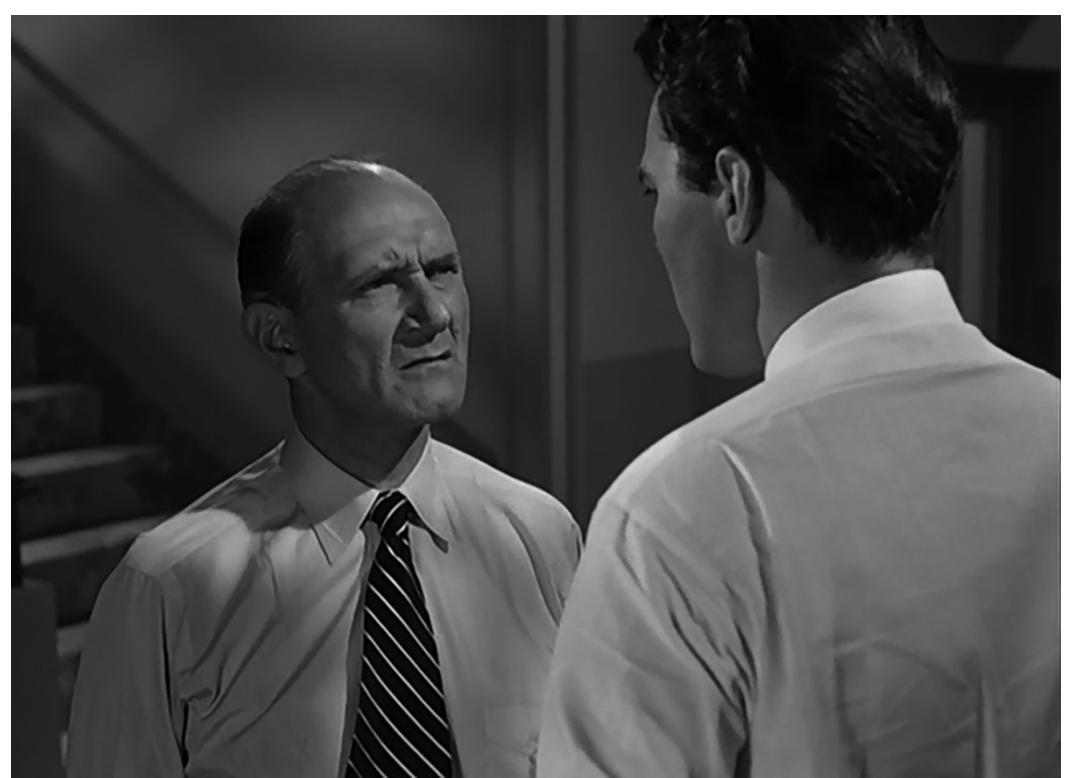

Fotograma 8. Recordando las enfermedades de la Edad Media esos síntomas se corresponden con los de la viruela 


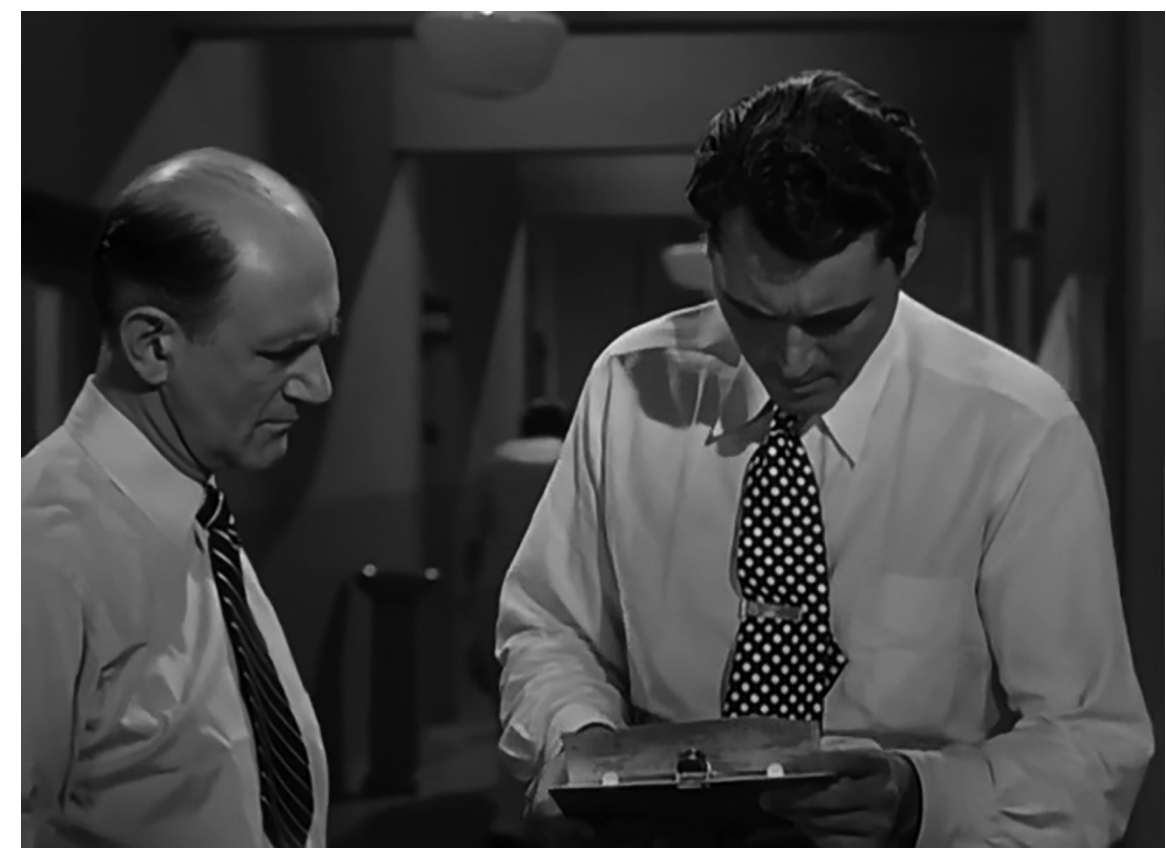

Fotograma 9. La niña nunca había sido vacunada

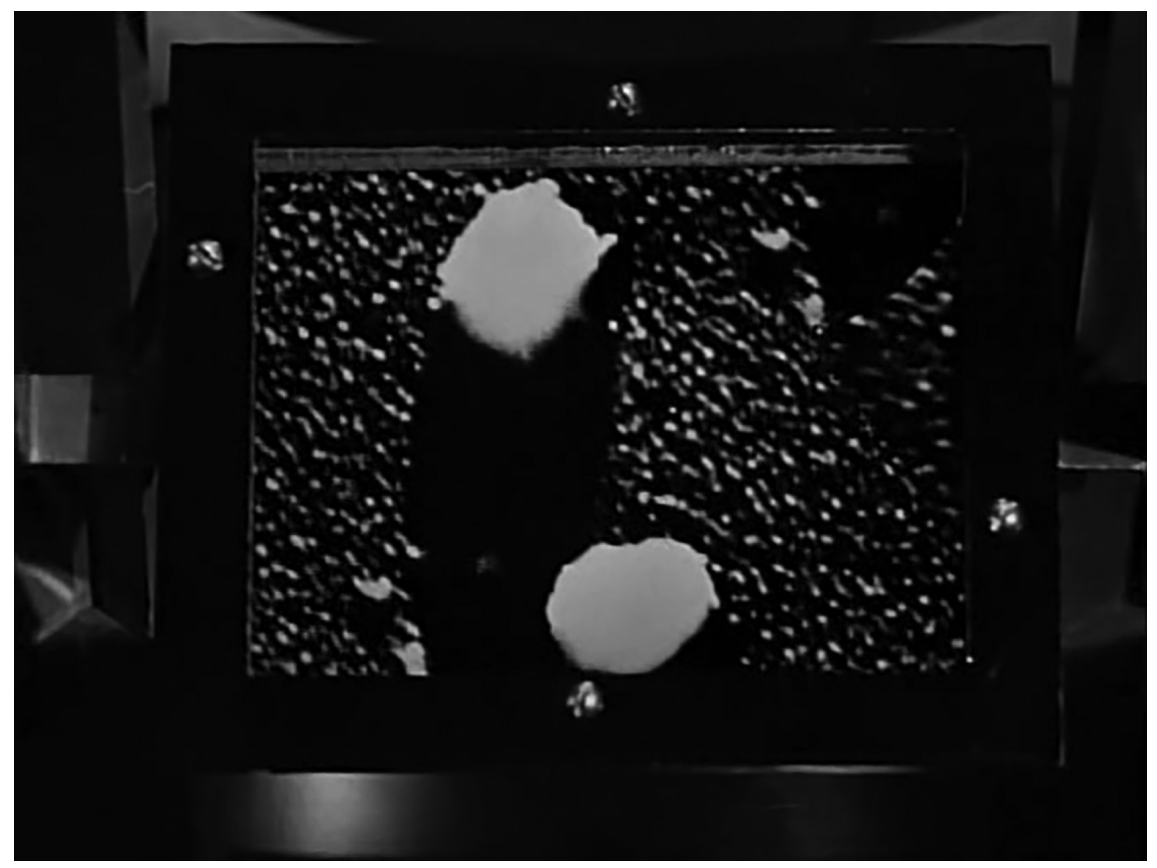

Fotograma 10. Diagnostico etiológico por microscopia electrónica 


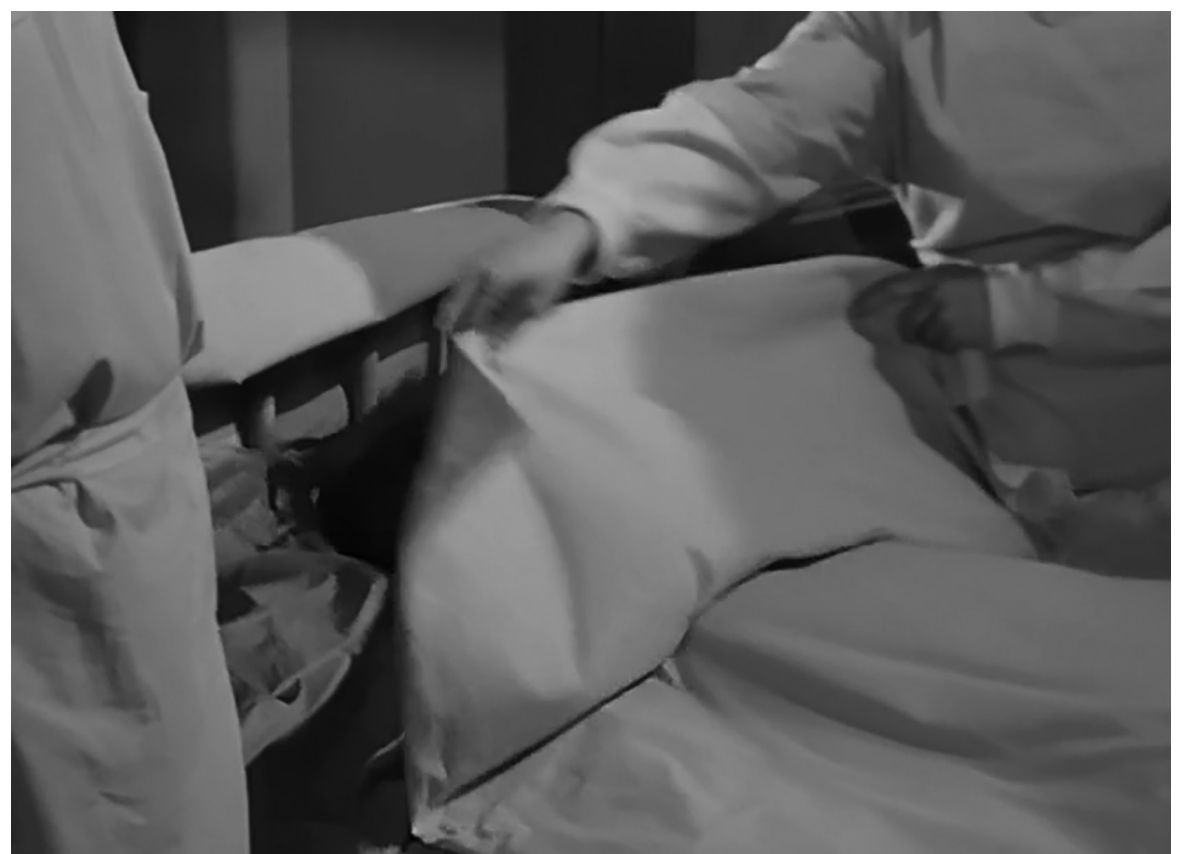

Fotograma 11. La viruela es una enfermedad infecciosa que produce una elevada mortalidad

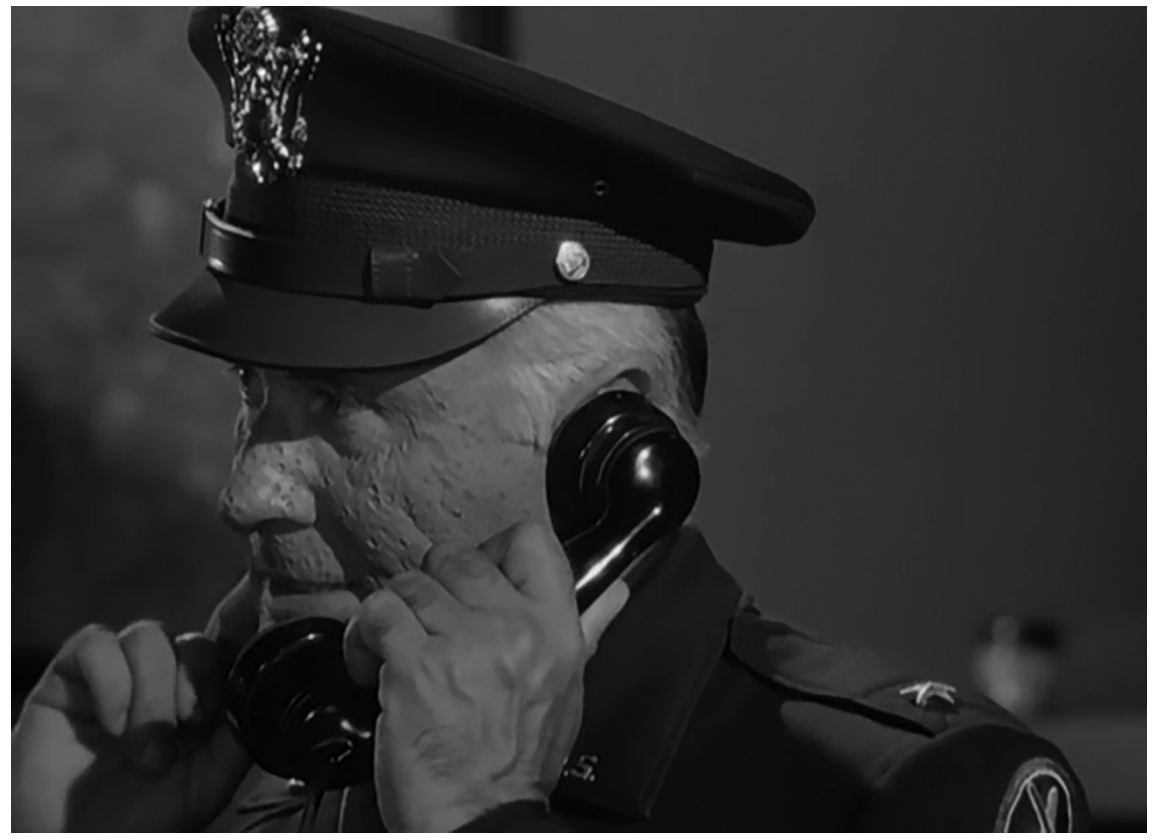

Fotograma 12. A los supervivientes le pueden quedar cicatrice (Cara picada de viruelas) 


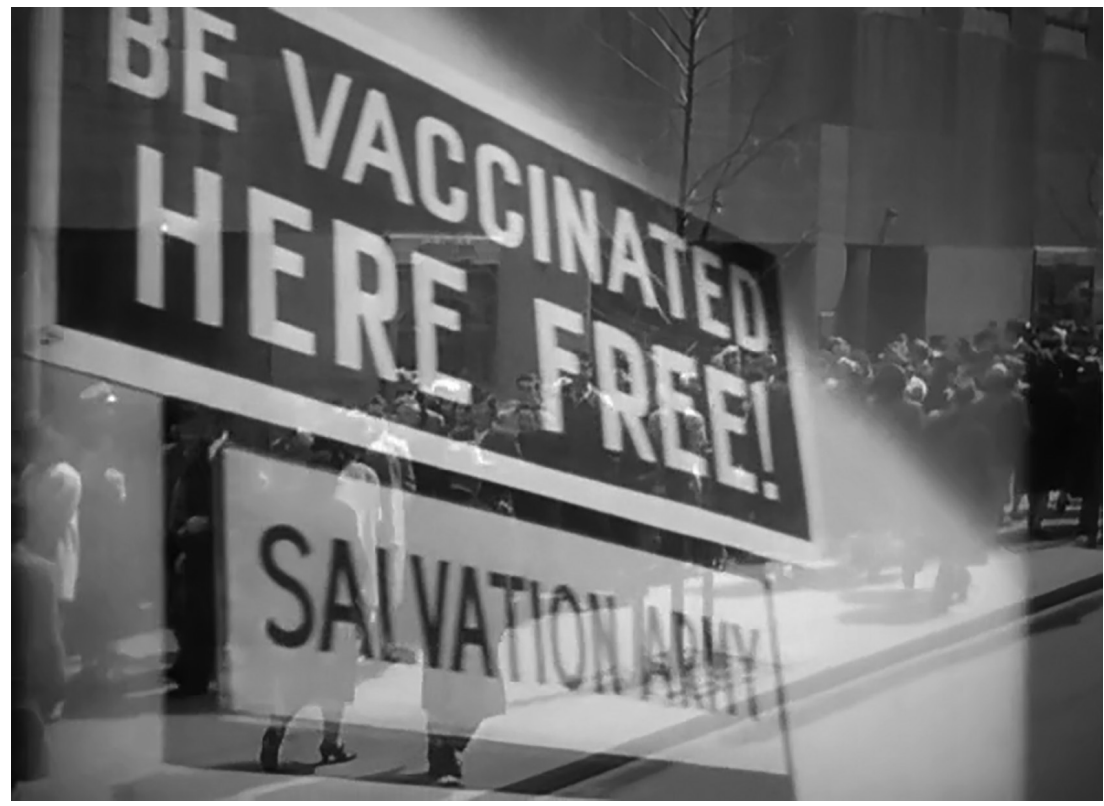

Fotograma 13. Prevención: vacuna

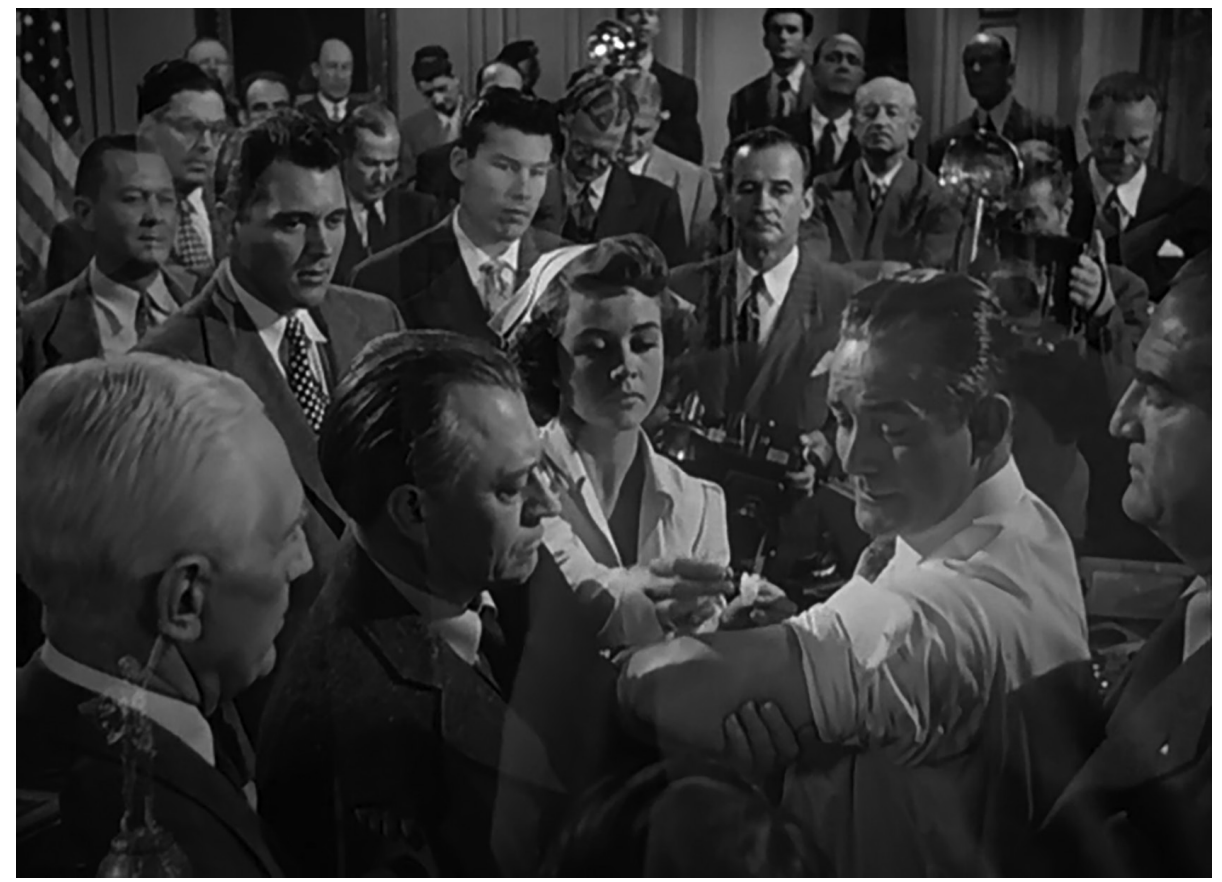

Fotograma 14. Vacunación por escarificación 